Original Paper http://ajol.info/index.php/ijbcs http://indexmedicus.afro.who.int

\title{
Evaluation des activités polyphénoloxydases, peroxydases et l'accumulation des composés phénoliques dans la résistance du manioc stimulé au Benzo $(1,2,3)$ thiadiazol-7-carbothionic acid-s-méthyl ester vis-à-vis de Colletotrichum gloeosporioides Penz
}

\author{
Hubert DieuBéni ELIAN ${ }^{1,4^{*}}$, FOTSO ${ }^{1,2}$, Astrid Carole DJEUANI ${ }^{1,3}$, \\ Djasbé Mathurin DJAMNDO $^{4}$ et Ndoumou Denis OMOKOLO ${ }^{1}$
}

\author{
${ }^{1}$ Laboratoire de Physiologie végétale. Ecole Normale Supérieure, Université de Yaoundé 1. BP: 47, \\ Yaoundé, Cameroun. \\ ${ }^{2}$ Département de Biologie, Ecole Normale Supérieure, Bambili, Université de Bamenda, BP: 39, \\ Bamenda, Cameroun. \\ ${ }^{3}$ Département de Biologie et Physiologie Végétales, Faculté des Sciences, Université de Yaoundé 1. BP: \\ 812, Yaoundé, Cameroun. \\ ${ }^{4}$ Département d'Agriculture, Institut Supérieur de Développement Rural (ISDR) de Mbaiki, Université de \\ Bangui, BP: 1450 Bangui, République Centrafricaine. \\ *Auteur correspondant ; E-mail: eliandieubeni@gmail.com; Tel.: (00)236 75012301 /(00)236 72126344
}

\begin{tabular}{lll}
\hline Received: 05-03-2021 & Accepted: 25-05-2021 & Published: 30-06-2021 \\
\hline
\end{tabular}

\section{RESUME}

Le manioc (Manihot esculenta Crantz) est une plante pluriannuelle cultivée dans les régions tropicales de la plupart des pays d'Afrique, d'Asie et d'Amérique Latine. Il contribue fortement à la sécurité alimentaire. L'objectif de cette étude est d'analyser le comportement des polyphénoloxydases (PPO), de la peroxydase (POX) et des composés phénoliques chez trois variétés de manioc au cours de leur induction au Benzo $(1,2,3)$ thiadiazol7-carbothionic acid-s-methyl ester (BTH) vis-à-vis de $C$. gloeosporioides. L'induction de résistance a été évaluée par des PPO, de la POX et de la teneur en composés phénoliques totaux solubles accumulés avant et après l'inoculation (I) par C. gloeosporioides, la stimulation (St) par BTH et de la stimulation suivie de l'inoculation $(\mathrm{St}+\mathrm{I})$. Avec les différents traitements, on note une augmentation progressive et significative $(\mathrm{p}<0,05)$ de l'activité de ces enzymes et des teneurs en phénols dans les feuilles et les tiges chez les trois variétés. Ces résultats montrent bien que le BTH stimule les mécanismes de défenses des plantes de manioc, bien que ces mécanismes diffèrent en fonction des variétés.

(c) 2021 International Formulae Group. All rights reserved.

Mots clés : Manihot esculenta, Colletotrichum gloeosporioides, induction, résistance, BTH, PPO, POX, Composé phénolique. 


\title{
Evaluation of polyphenoloxidase and peroxidase activities and accumulation of phenolic compounds in the resistance of stimulated cassava to Benzo $(1,2,3)$ thiadiazol-7-carbothionic acid-s-methyl ester against Colletotrichum gloeosporioides Penz.
}

\begin{abstract}
Cassava (Manihot esculenta Crantz) is a perennia plant cultivated in the tropical regions of most countries in Africa, Asia and Latin America. It contributes strongly to food security. The aim of this study was to analyze the behavior of polyphenoloxidases (PPO), peroxidase (POX) and phenolic compounds in three cassava varieties during their induction to Benzo $(1,2,3)$ thiadiazol-7-carbothionic acid-s-methyl ester (BTH) against $C$. gloeosporioides. Resistance induction was evaluated by PPO, POX and total soluble phenolic compounds content accumulated before and after inoculation (I) with C. gloeosporioides, stimulation (St) with BTH and stimulation followed by inoculation $(\mathrm{St}+\mathrm{I})$. With the different treatments, there was a progressive and significant $(\mathrm{p}<0.05)$ increase in the activity of these enzymes and in the phenol contents in the leaves and stems of the three varieties. These results show that BTH stimulates the defense mechanisms of cassava plants, although these mechanisms differ according to the varieties.
\end{abstract}

(C) 2021 International Formulae Group. All rights reserved.

Keywords: Manihot esculenta, Colletotrichum gloeosporioides, induction, resistance, BTH, PPO, POX, Phenolic compound.

\section{INTRODUCTION}

Le manioc (Manihot esculenta Crantz) est une plante pluriannuelle cultivée dans les régions tropicales de la plupart des pays d'Afrique, d'Asie et d'Amérique Latine (Ravi et al., 1996). La facilité de culture de cette plante, sa capacité d'adaptation à différents types de sols et sa tolérance à la sécheresse ont contribué à l'expansion de sa culture (Coulibaly et Séry, 1992). Cette plante est cultivée pour ses tubercules amylacés qui fournissent de la nourriture à plus de 500 millions de personnes à travers le monde et particulièrement dans les pays tropicaux (Kumba, 2012).

Pour accroître aussi la production, plusieurs cultivars ont été vulgarisés. Cependant, le manioc est tributaire de nombreuses contraintes qui freinent le développement de la filière. Compte tenu de l'importance agricole, alimentaire et économique du manioc, les parasites qui affectent sa croissance, affectent par contrecoup les populations de nombreux pays qui exploitent cette denrée. Ces contraintes sont principalement liées aux maladies telles que l'anthracnose provoquée par un champignon Colletotrichum gloeosporioides $\mathrm{f}$. sp. Manihotis, qui est la première maladie caulinaire d'Afrique et se rencontre dans les principales régions productrices du manioc. D'après certains auteurs (Makambila, 1984; Guthrie, 2004), un coréide piqueur, Pseudotheraptus devastans, serait partiellement impliqué dans la propagation de la maladie. Ces maladies peuvent occasionner des pertes de rendements allant de $80 \%$ à $100 \%$ (Dogbo et al., 2008).

Les plantes sont capables de se défendre contre les attaques des pathogènes à travers une variété de mécanismes de défenses préexistants et induits. Ceci nécessite la perception des molécules signalées, résultantes de l'attaque par les pathogènes (Jourdan et al. 2008) et permet à la plante de se développer et de réagir face à ces attaques. Parmi ces stratégies, il y a la résistance induite basée sur le concept de préimmunisation (Mbouobda, 2013). Elle consiste à éveiller ou stimuler les mécanismes de défense des plantes vis-à-vis de l'agent pathogène, soit en des traitements par des microorganismes non pathogènes, soit en des 
traitements par des substances chimiques ou biologiques.

Par ailleurs, lorsque les plantes sont attaquées, elles réagissent par des modifications du métabolisme. Ces modifications peuvent se manifester au point d'inoculation de l'agent pathogène par une nécrose entourée de cellules vivantes devenues résistantes aux microorganismes. Ces cellules ont leurs parois renforcées par des dépôts de callose, de lignines et d'autres composés phénoliques (Housti et al., 2002; Majourhat et al., 2002). De multiples enzymes sont activées, entre autres, la phénylalanine ammonia-lyase (PAL) et les polyphénoloxydases (PPO). De nombreuses voies biochimiques sont stimulées et le métabolisme secondaire s'accroît. L'ensemble de ces réactions constitue la réponse d'hypersensibilité $(\mathrm{RH})$. Elle apparaît après la reconnaissance de l'agent pathogène chez les plantes résistantes. Cette réponse induit parallèlement la synthèse de certaines molécules comme le Benzo (1,2,3)thiadiazole-7-carbothioic acid S-methyl ester (BTH), qui est un éliciteur pouvant améliorer la résistance aux maladies chez le manioc, le tabac (Nicotiana tabacum), le blé (Triticum sativum) et d'autres plantes agricoles importantes ( Xiaochun et al. 2021). Lorsqu'il atteint une concentration adéquate, il déclenche les réactions de défense dans toutes les parties de la plante. On parle alors de réaction systémique acquise (RSA) (Métraux et al., 1990; Métraux, 2001).

Les PPO catalysent l'oxydation des phénols en o-quinones qui réagissent avec les acides aminés et les protéines. Ceux-ci, après polymérisation, donnent des composés complexes qui sont à l'origine du brunissement des tissus (Concellün et al., 2004, Colak et al., 2005, Schweiggert et al., 2005). Par leur capacité à produire les quinones, les PPO font partie des armes défensives des plantes vis-àvis des agents pathogènes et des stress abiotiques, et sont généralement considérés comme des marqueurs biochimiques de résistance (Constabel et al., 2000). Les peroxydases ont été fréquemment utilisées comme marqueurs biochimiques de la résistance au stress (Elian, 2017). Les stress imposés à la plante par la présence des germes pathogènes ont une influence sur l'activité peroxydasique. Les phénols jouent un rôle capital dans la défense des plantes et toutes les classes des composés qui sont impliqués (Djocgoué et al., 2007). L'objectif de ce travail est d'analyser le comportement de PPO, peroxydase (POX) et des composés phénoliques chez trois variétés de manioc au cours de leur induction au BTH vis-à-vis de Colletotrichum gloeosporioides Penz.

\section{MATERIEL ET METHODES Matériel végétal}

Le matériel végétal était constitué de boutures de trois variétés de manioc de sensibilités différentes à l'anthracnose : sensible, résistante intermédiaire et résistante élevée provenant des champs d'expérimentation de l'IITA à Nkolbisson, Yaoundé (Cameroun). Il s'agit respectivement des variétés TMS 96/0023, TMS $92 / 0326$ et TMS 95/0211.

\section{Matériel fongique}

Le matériel fongique était constitué des souches de Colletotrichum gloeosporioides isolées à partir des tiges de manioc infectées, provenant des champs d'expérimentation de l'IITA à Nkolbisson, Yaoundé (Cameroun).

\section{Méthodes}

\section{Effet de BTH sur les plantes de manioc}

La méthode de traitement des plantes issues des vitroplants utilisées est celle décrite par Mbouobda (2013). Les plantules de chacun des deux cultivars, âgées de 2 mois et ne présentant aucun signe d'infection visible étaient divisées en 4 lots:

- un lot de plantules témoins qui ne subissent aucun traitement (S);

- un lot de plantules inoculées avec le mycélium de $C$. gloeosporioides (I);

- un lot de plantules stimulées au BTH (St). 
- un lot de plantules inoculées avec le mycélium de C. gloeosporioides après stimulation au BTH (St+I).

Pour chaque traitement, trois essais étaient menés de manière indépendante. L'inoculation consiste à déposer au niveau de la rhizosphère de la plantule, $5 \mathrm{ml}$ d'une suspension mycélienne. La concentration de l'inoculum (un mélange de zoospores et de fragments mycéliens) a été préalablement déterminée par une série de dilution sur PD. Pour préparer l'inoculum, le mycélium fongique et les zoospores (conidies) développées sur PDA en boite de Pétri 4 jours à $27^{\circ} \mathrm{C} \pm 1$ étaient mélangés dans de l'eau stérile et placés à $4{ }^{\circ} \mathrm{C}$ pendant $15 \mathrm{mn}$ (chaque boite dans $500 \mathrm{ml}$ d'eau). Cette solution était utilisée pour inoculer les plantes, à raison de $100 \mathrm{ml} \mathrm{du}$ mélange mycélien/zoospores par pot contenant une plante. Le traitement au BTH consiste à pulvériser chaque plantule avec $10 \mathrm{ml}$ d'une solution de BTH à $0,2 \mathrm{mg} / \mathrm{ml}$. La plante entière est traitée.

Pour les analyses biochimiques, les feuilles des plantes issues des vitroplants ont été prélevées tous les 2 jours pendant 10 jours. Les tiges ont été également prélevées dans la même période. Elles ont été lavées à l'eau de robinet, essorées, pesées et stockées à $-4{ }^{\circ} \mathrm{C}$ pour les analyses ultérieures.

\section{Extraction des protéines totales solubles}

L'extraction des protéines totales a été réalisée selon la méthode décrite par Mbouobda et al. (2007). Deux grammes de matériel végétal ont été broyés à froid $\left(4{ }^{\circ} \mathrm{C}\right)$ dans un mortier en porcelaine contenant $4 \mathrm{ml}$ $\mathrm{du}$ tampon TAMET (Tris 0,5 $\mathrm{M}$, acide ascorbique $0,3 \mathrm{M}, \beta$-mercaptoéthanol $2 \%$, EDTA $0,01 \mathrm{M}$, Triton $\mathrm{x} 100(2 \%) \mathrm{pH} 7)$ additionné du polyvinyl pyrrolidone (PVP) et du sable fin (stérile). Le broyat est incubé pendant $30 \mathrm{mn}$, puis centrifugé à $10000 \mathrm{~g}$ pendant $30 \mathrm{mn}$ et à $4{ }^{\circ} \mathrm{C}$. Le surnageant recueilli constitue l'extrait protéique total soluble. Ce surnageant a été stocké dans les tubes Eppendorf et conservé à $-20{ }^{\circ} \mathrm{C}$ pour les analyses ultérieures.

\section{Dosage de l'activité peroxydases (POX)}

Le dosage des peroxydases a été fait selon la méthode de Thorpe et al. (1978). Le milieu réactionnel a été constitué de - 1 volume de $\mathrm{H}_{2} \mathrm{O}_{2}$ à $0,2 \%(\mathrm{~V} / \mathrm{V})$ puis 2 volumes de Gaïacol à $1 \%(\mathrm{~V} / \mathrm{V})$ et 5 volumes de tampon phosphate, 0,06 M, pH 6.8.

Dans chaque tube à essai, on a introduit $5 \mathrm{ml} \mathrm{du}$ milieu réactionnel, $10 \mu \mathrm{L}$ d'extrait. Après homogénéisation, l'activité a été déterminée en suivant la formation du tetragaïacol à partir du gaïacol. L'absorbance a été lue à $420 \mathrm{~nm}$ au spectrophotomètre contre un blanc dans lequel l'extrait a été remplacé par le tampon d'extraction. Trois lectures ont été faites par échantillon. La teneur en POX est exprimée en $\triangle \mathrm{DO} \cdot \mathrm{mn}^{-1} \mathrm{~g}^{-1}$ de PF (coefficient d'extinction molaire des peroxydases $\epsilon=26,6$ M.cm ${ }^{-1}$ ).

Dosage des activités polyphénoloxydases (PPO)

Le dosage des PPO a été fait selon la méthode décrite par Mayer et al. (1965) modifiée. On a mis dans chaque tube et dans l'ordre suivant: $2 \mathrm{ml}$ du tampon phosphate 0,1 $\mathrm{M} \mathrm{pH} \mathrm{6,5} \mathrm{puis10} \mu 1$ de l'extrait enzymatique. La réaction a été déclenchée par ajout de $10 \mu \mathrm{l}$ de la solution de catéchol (substrat) 0,2 M, la lecture de la densité a été faite après $3 \mathrm{mn}$ à de $410 \mathrm{~nm}$ contre un blanc dans lequel l'extrait a été remplacé par le tampon phosphate. Pour chaque extrait, trois lectures ont été effectuées et l'activité PPO est exprimée en $\Delta$ DO. $\mathrm{mn}^{-1} \cdot \mathrm{g}^{-1}$ de PF.

\section{Extraction des composées phénoliques}

Les composés phénoliques ont été extraits selon la méthode décrite par Mbouobda (2013). $1 \mathrm{~g}$ de matériel végétal a été broyé dans un mortier en porcelaine et à froid $\left(4^{\circ} \mathrm{C}\right)$, dans un volume de $3 \mathrm{ml}$ de méthanol $80^{\circ}$ en présence du sable fin (stérile). L'extrait a été incubé pendant $30 \mathrm{mn}$ à $4{ }^{\circ} \mathrm{C}$ puis centrifugé à 10000 g pendant $20 \mathrm{mn}$ et à $4{ }^{\circ} \mathrm{C}$. Le surnageant récupéré constitue l'extrait brut des composés phénoliques. Ce surnageant a été stocké dans des tubes Eppendorfs et conservé à $-20^{\circ} \mathrm{C}$ pour le dosage. 


\section{Dosage des phénols totaux}

Le dosage des phénols a été réalisé suivant la méthode de Marigo et al. (1973). Dans chaque tube à essai on introduit dans l'ordre suivant: $100 \mu \mathrm{l}$ d'extrait puis $1750 \mu 1$ d'eau distillée et $250 \mu \mathrm{l}$ de Folin dilué à moitié (1/2). Le mélange a été agité pendant $3 \mathrm{mn}$, puis $500 \mu \mathrm{l}$ de carbonate de sodium $20 \%$ ont été ajoutés, ensuite on agite pendant $3 \mathrm{mn}$ et on incube à $40{ }^{\circ} \mathrm{C}$ pendant $30 \mathrm{mn}$. Après refroidissement, la densité optique a été lue à $760 \mathrm{~nm}$ contre un blanc dans lequel l'extrait a été remplacé par l'eau distillée. La teneur en composés phénoliques a été exprimée en $\mu \mathrm{g}$ équivalent de catéchine. $\mathrm{g}^{-1}$.PF.

\section{Analyse statistique}

Toutes les données obtenues après différentes analyses biochimiques ont fait l'objet d'une analyse par ANOVA, en utilisant le logiciel SPSS 20 pour Windows. Le test de Turkey a été utilisé pour déterminer toute différence significative entre les différentes variétés au seuil de $p<0,05$. Les résultats ont été exprimés sous forme de moyennes \pm l'écarttype. Toutes les expériences ont été réalisées en quatre répétitions.

\section{RESULTATS}

\section{Variation des activités polyphénoloxydasiques solubles (PPO)}

L'activité de PPO a été mesurée tant dans les feuilles saines que dans les tiges saines des trois variétés. En l'absence de tout traitement (S), elle a été plus élevée et on a noté une augmentation progressive au cours de l'essai du jour 0 au jour 8 chez toutes les variétés. Chez la variété TMS 96/0023, elle est passée de $5,18 \pm 1,50 \mu \mathrm{M} \cdot \mathrm{mn}^{-1} \cdot \mathrm{ml}^{-1}$ à $6,35 \pm 0,10 \mu \mathrm{M} \cdot \mathrm{mn}^{-1} \cdot \mathrm{ml}^{-1}$ et de $3,95 \pm 0,50$ $\mu \mathrm{M} \cdot \mathrm{mn}^{-1} \cdot \mathrm{ml}^{-1}$ à $5,68 \pm 0,05 \mu \mathrm{M} \cdot \mathrm{mn}^{-1} \cdot \mathrm{ml}^{-1}$ et chez

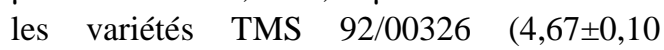
$\mu \mathrm{M} \cdot \mathrm{mn}^{-1} \cdot \mathrm{ml}^{-1}$ à $5,72 \pm 0,10 \mu \mathrm{M} \cdot \mathrm{mn}^{-1} \cdot \mathrm{ml}^{-1}$ et de $4,42 \pm 0,50 \quad \mu \mathrm{M} \cdot \mathrm{mn}^{-1} \cdot \mathrm{ml}^{-1} \quad$ à $\quad 4,90 \pm 0,45$ $\left.\mu \mathrm{M} \cdot \mathrm{mn}^{-1} \cdot \mathrm{ml}^{-1}\right)$ et TMS 95/0211 (3,42 $\pm 0,60$ $\mu \mathrm{M} \cdot \mathrm{mn}^{-1} \cdot \mathrm{ml}^{-1}$ à $6,14 \pm 0,20 \mu \mathrm{M} \cdot \mathrm{mn}^{-1} \cdot \mathrm{ml}^{-1}$ et de $3,02 \pm 0,15 \quad \mu \mathrm{M} \cdot \mathrm{mn}^{-1} \cdot \mathrm{ml}^{-1} \quad 3,49 \pm 0,55$ $\mu \mathrm{M} \cdot \mathrm{mn}^{-1} \cdot \mathrm{ml}^{-1}$ ) respectivement dans les feuilles et les tiges (Tableaux 1 et 2).
En condition d'inoculation (I) avec $C$. gloeosporioides, on a enregistré une augmentation de l'activité de PPO soluble chez la variété TMS 96/0023 $\quad(5,33 \pm 1,24$ $\mu \mathrm{M} \cdot \mathrm{mn}^{1} \cdot \mathrm{ml}^{-1}$ et $3,90 \pm 1,06 \mu \mathrm{M} \cdot \mathrm{mn}^{-1} \cdot \mathrm{ml}^{-1}$ ) au jour 0 , respectivement dans les feuilles et les tiges. Elle a augmenté progressivement les autres jours. Chez la variété TMS 92/0326, l'augmentation de l'activité a été progressive dans les feuilles; elle est passée de 3,99 $\pm 0,18$ $\mu \mathrm{M} \cdot \mathrm{mn}^{-1} \cdot \mathrm{ml}^{-1}$ au jour 0 à $8,89 \pm 0,10$ $\mu \mathrm{M} \cdot \mathrm{mn}^{-1} \cdot \mathrm{ml}^{-1}$ au jour 8 , tandis qu' au niveau des tiges, elle a atteint un pic maximal au jour 2 $\left(7,06 \pm 0,50 \mu \mathrm{M} \cdot \mathrm{mn}^{-1} \cdot \mathrm{ml}^{-1}\right)$ puis a baissé. Chez la variété TMS 95/0211, une augmentation progressive a été est notée du jour $0(3,51 \pm 0,39$ $\left.\mu \mathrm{M} \cdot \mathrm{mn}^{-1} \cdot \mathrm{ml}^{-1}\right) \quad$ au jour $8 \quad(5,36 \pm 0,28$ $\mu \mathrm{M} \cdot \mathrm{mn}^{-1} \cdot \mathrm{ml}^{-1}$ ) au niveau des feuilles, tandis qu'au niveau des tiges, elle a augmenté progressivement du jour $0 \quad(3,07 \pm 0,32$ $\mu \mathrm{M} \cdot \mathrm{mn}^{-1} \cdot \mathrm{ml}^{-1}$ ) au jour $8(9,21 \pm 0,39)$ (Tableaux 1 et 2).

Lorsque les plantes ont été traitées au BTH (St), l'activité de PPO soluble a augmenté significativement chez la variété TMS 96/0023. Elle est passée de 5,79 $\pm 0,07$ $\mu \mathrm{M} \cdot \mathrm{mn}^{-1} \cdot \mathrm{ml}^{-1}$ au jour 0 à $8,68 \pm 0,14$ $\mu \mathrm{M} \cdot \mathrm{mn}^{-1} \cdot \mathrm{ml}^{-1}$ au jour 8 dans les feuilles; par contre, elle a atteint un pic maximal d'activité au jour $4\left(9,03 \pm 0,21 \mu \mathrm{M} \cdot \mathrm{mn}^{-1} \cdot \mathrm{ml}^{-1}\right)$ dans les tiges puis a baissé progressivement. Chez la variété TMS 92/0326, des pics maxima ont été notés au jour $4\left(7,37 \pm 0,04 \mu \mathrm{M} \cdot \mathrm{mn}^{-1} \cdot \mathrm{ml}^{-1}\right)$ et au jour $8\left(8,89 \pm 0,07 \mu \mathrm{M} \cdot \mathrm{mn}^{-1} \cdot \mathrm{ml}^{-1}\right)$ au niveau des feuilles, tandis qu'au niveau des tiges, elle a augmenté du jour $0\left(4,27 \pm 1,31 \mu \mathrm{M} \cdot \mathrm{mn}^{-1} \cdot \mathrm{ml}^{-1}\right)$ au jour $4\left(7,62 \pm 0,49 \mu \mathrm{M} \cdot \mathrm{mn}^{-1} \cdot \mathrm{ml}^{-1}\right)$ puis a baissé légèrement. Chez la variété TMS 95/0211, les pics maxima de cette activité ont été notés au jour $4\left(7,62 \pm 0,49 \mu \mathrm{M} \cdot \mathrm{mn}^{-1} \cdot \mathrm{ml}^{-1}\right)$ et au jour $8\left(8,08 \pm 0,04 \mu \mathrm{M} \cdot \mathrm{mn}^{-1} \cdot \mathrm{ml}^{-1}\right)$ au niveau des feuilles, par contre dans les tiges, elle a augmenté significativement du jour 0 $\left(4,09 \pm 0,20 \mu \mathrm{M} \cdot \mathrm{mn}^{-1} \cdot \mathrm{ml}^{-1}\right)$ au jour $4(8,08 \pm 0,04$ $\left.\mu \mathrm{M} \cdot \mathrm{mn}^{-1} \cdot \mathrm{ml}^{-1}\right)$, ensuite a baissé au jour 6 $\left(6,95 \pm 0,21 \mu \mathrm{M} \cdot \mathrm{mn}^{-1} \cdot \mathrm{ml}^{-1}\right)$ puis a augmenté au jour $8\left(11,93 \pm 0,25 \mu \mathrm{M} \cdot \mathrm{mn}^{-1} \cdot \mathrm{ml}^{-1}\right)$ (Tableaux 1 et 2).

Chez les plantes inoculées après stimulation au BTH $(\mathrm{St}+\mathrm{I})$, l'activité de PPO 
soluble a été plus importante dans les feuilles que dans les tiges au cours de l'essai chez TMS 96/0023 et TMS 0326, alors que le contraire a été observé chez TMS 92/0211. Chez TMS 96/0023, on a noté une activité significative des pics maxima respectivement $(8,01 \pm 0,11$ $\mu \mathrm{M} \cdot \mathrm{mn}^{-1} \cdot \mathrm{ml}^{-1}$ et $\left.8,29 \pm 0,60 \mu \mathrm{M} \cdot \mathrm{mn}^{-1} \cdot \mathrm{ml}^{-1}\right)$ aux jours 4 et 8 dans les feuilles tandis que dans les tiges le pic maximal a été noté au jour 2 $\left(8,08 \pm 1,24 \mu \mathrm{M} \cdot \mathrm{mn}^{-1} \cdot \mathrm{ml}^{-1}\right)$ puis a baissé légèrement. Chez la variété TMS 92/0326, cette activité a augmenté progressivement au niveau des feuilles. Elle est passée de $5,36 \pm 0,07 \mu \mathrm{M} \cdot \mathrm{mn}^{-1} \cdot \mathrm{ml}^{-1}$ au jour 0 à $7,83 \pm 0,10$ $\mu \mathrm{M} \cdot \mathrm{mn}^{-1} \cdot \mathrm{ml}^{-1}$ au jour 4 puis a baissé, par contre elle a atteint un pic maximal $(8,50 \pm 0,18$ $\left.\mu \mathrm{M} \cdot \mathrm{mn}^{-1} \cdot \mathrm{ml}^{-1}\right)$ au jour 4 et au jour $8(9,07 \pm 0,32$ $\mu \mathrm{M} \cdot \mathrm{mn}^{-1} \cdot \mathrm{ml}^{-1}$ ) puis a baissé progressivement après au niveau des tiges. Chez la variété TMS $95 / 0211$, on a enregistré un pic maximal $\left(8,50 \pm 1,45 \mu \mathrm{M} \cdot \mathrm{mn}^{-1} \cdot \mathrm{ml}^{-1}\right)$ au jour 0 et au jour 8 $\left(9,24 \pm 0,07 \quad \mu \mathrm{M} \cdot \mathrm{mn}^{-1} \cdot \mathrm{ml}^{-1}\right)$ au niveau des feuilles, alors qu' au niveau des tiges, elle a

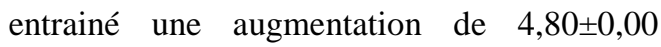
$\mu \mathrm{M} \cdot \mathrm{mn}^{-1} \cdot \mathrm{ml}^{-1}$ au jour 0 à $8,86 \pm 0,04$ $\mu \mathrm{M} \cdot \mathrm{mn}^{-1} \cdot \mathrm{ml}^{-1}$ au jour 4 puis abaisse au jour 6 $\left(5,61 \pm 0,04 \mu \mathrm{M} \cdot \mathrm{mn}^{-1} \cdot \mathrm{ml}^{-1}\right)$ ensuite a augmenté significativement au jour $8 \quad(9,763 \pm 0,21$ $\mu \mathrm{M} \cdot \mathrm{mn}^{-1} \cdot \mathrm{ml}^{-1}$ ) (Tableaux 1 et 2).

\section{Variation de l'activité peroxydase soluble (POX)}

L'activité de POX a été estimée dans les feuilles et dans les tiges des trois variétés de M. esculenta. En l'absence de tout traitement, chez la variété TMS 96/0023, on a enregistré une augmentation significative de l'activité de POX au niveau des feuilles. Elle était passée de $0,97 \pm 0,17 \mu \mathrm{M} \cdot \mathrm{mn}^{-1} \cdot \mathrm{ml}^{-1}$ au jour 0 à $1,32 \pm 0,06$ $\mu \mathrm{M} \cdot \mathrm{mn}^{-1} \cdot \mathrm{ml}^{-1}$ au jour 8. L'augmentation du même ordre a été observée au niveau des tiges de la même variété. Chez la variété TMS 96/0326, une augmentation de cette activité a été notée dans les deux parties de la plante. Elle était passée de $0,96 \pm 0,01 \mu \mathrm{M} \cdot \mathrm{mn}^{-1} \cdot \mathrm{ml}^{-1}$ et $1,32 \pm 0,10 \mu \mathrm{M} \cdot \mathrm{mn}^{-1} \cdot \mathrm{ml}^{-1}$ au jour 0 à $1,28 \pm 0,05$ $\mu \mathrm{M} \cdot \mathrm{mn}^{-1} \cdot \mathrm{ml}^{-1}$ et $\quad 1,21 \pm 0,52 \mu \mathrm{M} \cdot \mathrm{mn}^{-1} \cdot \mathrm{ml}^{-1}$ au jour 8 respectivement au niveau des feuilles et des tiges. Chez la variété TMS 95/0211, cette activité de POX a été passée de 0,92 $\pm 0,20$ $\mu \mathrm{M} \cdot \mathrm{mn}^{-1} \cdot \mathrm{ml}^{-1}$ à $1,09 \pm 0,41 \mu \mathrm{M} \cdot \mathrm{mn}^{-1} \cdot \mathrm{ml}^{-1}$ dans les feuilles et de $1,16 \pm 1,10 \mu \mathrm{M} \cdot \mathrm{mn}^{-1} \cdot \mathrm{ml}^{-1}$ à $1,89 \pm 0,19 \mu \mathrm{M} \cdot \mathrm{mn}^{-1} \cdot \mathrm{ml}^{-1}$ dans les tiges saines (Tableaux 3 et 4 ).

Lorsque les plantes ont été inoculées (I) avec C. gloeosporioides, l'activité de POX a été plus importante dans les tiges que dans les feuilles. Chez la variété TMS 96/0023, cette inoculation a entrainé une augmentation significative $\left(1,67 \pm 0,02 \mu \mathrm{M} \cdot \mathrm{mn}^{-1} \cdot \mathrm{ml}^{-1}\right.$ et $\left.1,97 \pm 0,23 \mu \mathrm{M} \cdot \mathrm{mn}^{-1} \cdot \mathrm{ml}^{-1}\right)$ au jour 0 et 4 respectivement, puis a baissé progressivement après, tandis qu'elle a augmenté progressivement au cours de l'essai au niveau des tiges $(\mathrm{P}<0,05)$. Elle était passée de $1,83 \pm 0,10 \mu \mathrm{M} \cdot \mathrm{mn}^{-1} \cdot \mathrm{ml}^{-1}$ au jour 0 à $2,92 \pm 0,15$ $\mu \mathrm{M} \cdot \mathrm{mn}^{-1} \cdot \mathrm{ml}^{-1}$ au jour 8 . Chez la variété TMS $92 / 0326$, un pic maximal de chute $(0,14 \pm 0,04$ $\left.\mu \mathrm{M} \cdot \mathrm{mn}^{-1} \cdot \mathrm{ml}^{-1}\right)$ de l'activité a été observé au jour 4 , au niveau des feuilles, et elle a augmenté progressivement au cours du temps au niveau des tiges (Tableaux 3 et 4 ).

Chez la variété TMS 95/0211, un pic maximal a été mesuré au niveau des feuilles $\left(2,73 \pm 0,02 \mu \mathrm{M} \cdot \mathrm{mn}^{-1} \cdot \mathrm{ml}^{-1}\right)$ au jour 4 , puis elle a baissé légèrement aux jours 6 et 8 . Au niveau des tiges de cette variété, le même pic maximal a été observé au jour 2 (2,06 $\pm 0,17$ $\left.\mu \mathrm{M} \cdot \mathrm{mn}^{-1} \cdot \mathrm{ml}^{-1}\right)$ puis a diminué significativement au cours du temps (Tableaux 3 et 4 ).

Le traitement des plantes au BTH, a entrainé une augmentation importante de l'activité de POX aux niveaux des tiges que des feuilles dans toutes les variétés. Ainsi, chez la variété TMS 96/0,023, une augmentation progressive et significative a été enregistrée au cours du temps $(\mathrm{P}<0,05)$ dans les deux organes

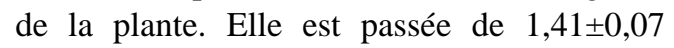
$\mu \mathrm{M} \cdot \mathrm{mn}^{-1} \cdot \mathrm{ml}^{-1}$ et $1,64 \pm 0,05 \mu \mathrm{M} \cdot \mathrm{mn}^{-1} \cdot \mathrm{ml}^{-1}$ à $2,71 \pm 0,14 \mu \mathrm{M} \cdot \mathrm{mn}^{-1} \cdot \mathrm{ml}^{-1} \quad$ et $3,01 \pm 0,46$ $\mu \mathrm{M} \cdot \mathrm{mn}^{-1} \cdot \mathrm{ml}^{-1}$ respectivement au niveau des feuilles et des tiges. Chez la variété TMS 92/0326, un pic maximal de chute a été noté au jour $6\left(0,54 \pm 0,15 \mu \mathrm{M} \cdot \mathrm{mn}^{-1} \cdot \mathrm{ml}^{-1}\right)$, et au jour 8 $\left(0,55 \pm 0,05 \mu \mathrm{M} \cdot \mathrm{mn}^{-1} \cdot \mathrm{ml}^{-1}\right)$ au niveau des feuilles, tandis qu'au niveau des tiges un pic maximal a été noté au jour $2(1,94 \pm 0,05$ $\left.\mu \mathrm{M} \cdot \mathrm{mn}^{-1} \cdot \mathrm{ml}^{-1}\right)$ et au jour $8 \quad(2,78 \pm 0,85$ $\mu \mathrm{M} \cdot \mathrm{mn}^{-1} \cdot \mathrm{ml}^{-1}$ ). Chez TMS 95/0211, on a noté 
une augmentation significative au niveau des feuilles de $1,42 \pm 0,37 \mu \mathrm{M} \cdot \mathrm{mn}^{-1} \cdot \mathrm{ml}^{-1}$ au jour 0 à $2,41 \pm 0,22 \mu \mathrm{M} \cdot \mathrm{mn}^{-1} \cdot \mathrm{ml}^{-1}$ au jour 4 , puis a baissé significativement au jour $6(0,59 \pm 0,25$ $\left.\mu \mathrm{M} \cdot \mathrm{mn}^{-1} \cdot \mathrm{ml}^{-1}\right)$. Par contre, au niveau des tiges, un pic maximal de chute a été observé au jour $4\left(0,27 \pm 0,02 \mu \mathrm{M} \cdot \mathrm{mn}^{-1} \cdot \mathrm{ml}^{-1}\right)$ (Tableaux 3 et 4 ).

Lorsque les plantes ont été traitées au BTH après inoculation à $C$. gloeosporioides, on a noté une augmentation significative de l'activité POX au cours du temps, tant aux niveaux des feuilles que des tiges des variétés TMS 96/0023 et 92/0326. Chez la variété TMS $95 / 0211$, on a observé une augmentation significative qui est passée de $2,08 \pm 0,27$ $\mu \mathrm{M} \cdot \mathrm{mn}^{-1} \cdot \mathrm{ml}^{-1} \quad$ au jour $0 \quad(2,66 \pm 0,01$ $\left.\mu \mathrm{M} \cdot \mathrm{mn}^{-1} \cdot \mathrm{ml}^{-1}\right)$ au jour 4 puis a baissé au jour 6 $\left(1,59 \pm 0,15 \mu \mathrm{M} \cdot \mathrm{mn}^{-1} \cdot \mathrm{ml}^{-1}\right)$ et au jour 8 $\left(1,79 \pm 0,25 \mu \mathrm{M} \cdot \mathrm{mn}^{-1} \cdot \mathrm{ml}^{-1}\right)$ au niveau des feuilles. Alors qu'au niveau des tiges une augmentation progressive a été enregistrée. Elle est passée de $0,73 \pm 0,09 \mu \mathrm{M} \cdot \mathrm{mn}^{-1} \cdot \mathrm{ml}^{-1}$ au jour 2 à $3,93 \pm 1,15 \mu \mathrm{M} \cdot \mathrm{mn}^{-1} \cdot \mathrm{ml}^{-1}$ au jour 8 (Tableaux 3 et 4 ).

\section{Variation de la teneur en phénols totaux solubles}

En l'absence de tout traitement, la teneur en phénols totaux solubles a augmenté progressivement au cours de l'essai chez les trois variétés. Chez la variété TMS 96/0023, elle est passée de 6,19 $\pm 1,27 \mu \mathrm{g}$ équivalent (+)catéchine. $\mathrm{mg}^{-1} \mathrm{PF}$ au jour 0 à $10,19 \pm 2,12 \mu \mathrm{g}$ équivalent $(+)$ - catéchine. $\mathrm{mg}^{-1} \mathrm{PF}$ au jour 8 et de 5,51 $\pm 1,07 \mu \mathrm{g}$ équivalent (+)- catéchine. $\mathrm{mg}^{-}$ ${ }^{1} \mathrm{PF}$ au jour 0 à $7,33 \pm 0,73 \mu \mathrm{g}$ équivalent $(+)$ catéchine. $\mathrm{mg}^{-1} \mathrm{PF}$ au jour 8 , respectivement dans les feuilles et tiges. Chez la variété TMS $92 / 0326$, elle a été de $6,01 \pm 0,85 \mu \mathrm{g}$ équivalent (+)- catéchine. $\mathrm{mg}^{-1} \mathrm{PF}$ au jour 0 à $9,57 \pm 0,35 \mu \mathrm{g}$ équivalent $(+)$ - catéchine. $\mathrm{mg}^{-1} \mathrm{PF}$ au jour 8 et de 4,00 $\pm 0,33 \mu \mathrm{g}$ équivalent (+)- catéchine. $\mathrm{mg}^{-}$ ${ }^{1} \mathrm{PF}$ au jour 0 à $7,17 \pm 1,57 \mu \mathrm{g}$ équivalent $(+)$ catéchine. $\mathrm{mg}^{-1} \mathrm{PF}$ au jour 8 , respectivement dans les feuilles et tiges. Chez la variété TMS 95/0211, elle est passée de 5,76 $\pm 0,29 \mu \mathrm{g}$ équivalent (+)- catéchine. $\mathrm{mg}^{-1} \mathrm{PF}$ au jour 0 à $8,68 \pm 0,09 \mu \mathrm{g}$ équivalent $(+)$ - catéchine. $\mathrm{mg}^{-1} \mathrm{PF}$ et de $3,38 \pm 0,04 \quad \mu \mathrm{g}$ équivalent $(+)$ catéchine. $\mathrm{mg}^{-1} \mathrm{PF}$ au jour 0 à $4,79 \pm 1,27 \mu \mathrm{g}$ équivalent (+)- catéchine. $\mathrm{mg}^{-1} \mathrm{PF}$ au jour 8 , respectivement dans les feuilles et tiges (Tableaux 5 et 6 ).

Lorsque les plantes ont été inoculées par C. gloeosporioides, on a noté une augmentation de cette teneur dans les deux organes des trois variétés. Chez la variété TMS 96/0023, un pic maximal a été noté au jour 6 $(11,71 \pm 0,29 \mu \mathrm{g}$ équivalent (+)- catéchine.mg${ }^{1} \mathrm{PF}$ ) au niveau des feuilles; par contre, au niveau des tiges, un pic de chute maximale a été observé au jour $2(1,04 \pm 0,36 \mu \mathrm{g}$ équivalent (+)- catéchine. $\left.\mathrm{mg}^{-1} \mathrm{PF}\right)$. Chez la variété TMS $92 / 0326$, on a enregistré des pics de chutes maximales au jour $4(4,43 \pm 1,14 \mu \mathrm{g}$ équivalent (+)- catéchine. $\left.\mathrm{mg}^{-1} \mathrm{PF}\right)$ et au jour $2(2,19 \pm 0,65$ $\mu \mathrm{g}$ équivalent (+)- catéchine. $\left.\mathrm{mg}^{-1} \mathrm{PF}\right)$, respectivement au niveau des feuilles et tiges. Chez la variété TMS 95/0211, la même tendance a été notée au jour $2(5,86 \pm 0,09 \mu \mathrm{g}$ équivalent (+)- catéchine. $\left.\mathrm{mg}^{-1} \mathrm{PF}\right)$ au niveau des feuilles et au jour $2(3,91 \pm 1,63 \mu \mathrm{g}$ équivalent (+)- catéchine. $\mathrm{mg}^{-1} \mathrm{PF}$ ) au niveau des tiges (Tableaux 5 et 6 ).

En condition de stimulation au BTH (St), on a enregistré une variation significative $(\mathrm{P}<0,05)$ de la teneur en composés phénoliques dans les deux organes des trois variétés. Au niveau des feuilles de la variété TMS 96/0023, elle a atteint un pic au jour $0(11,21 \pm 0,01 \mu \mathrm{g}$ équivalent (+)- catéchine. $\left.\mathrm{mg}^{-1} \mathrm{PF}\right)$ et au jour 6 $\left(12,16 \pm 0,28 \mu \mathrm{g}\right.$ équivalent $(+)$ - catéchine. $\mathrm{mg}^{-1}$ $\mathrm{PF})$, tandis qu'au niveau des tiges, un pic de chute a été noté au jour $2(3,41 \pm 0,80 \mu \mathrm{g}$ équivalent (+)- catéchine. $\left.\mathrm{mg}^{-1} \mathrm{PF}\right)$. Chez la variété TMS 92/0326, la teneur a atteint un maximum au jour 0 et $8(11,36 \pm 1,90 \mu \mathrm{g}$ équivalent (+)- catéchine. $\mathrm{mg}^{-1} \quad \mathrm{PF}$ et $11,23 \pm 0,64 \mu \mathrm{g}$ équivalent (+)- catéchine. $\mathrm{mg}^{-1}$ $\mathrm{PF}$ ) au niveau des feuilles tandis qu'au niveau des tiges, une baisse maximale a été notée au jour $6 \quad(0,98 \pm 0,09 \quad \mu \mathrm{g}$ équivalent (+)catéchine. $\left.\mathrm{mg}^{-1} \mathrm{PF}\right)$. Chez la variété TMS $95 / 0211$, on a enregistré un pic maximal aux jours 4 et $8 \quad(9,34 \pm 2,46 \mu \mathrm{g}$ équivalent (+)catéchine. $\mathrm{mg}^{-1} \mathrm{PF}$ et $10,06 \pm 0,53 \mu \mathrm{g}$ équivalent (+)- catéchine. $\mathrm{mg}^{-1} \mathrm{PF}$ ) au niveau des feuilles alors qu'on a observé la même tendance aux jours 4 et $8 \quad(7,86 \pm 0,37 \mu \mathrm{g}$ équivalent (+)catéchine. $\mathrm{mg}^{-1} \mathrm{PF}$ et $8,01 \pm 0,12 \mu \mathrm{g}$ équivalent 
(+)- catéchine. $\left.\mathrm{mg}^{-1} \mathrm{PF}\right)$ au niveau des tiges (Tableaux 5 et 6 ).

Lorsque les plantes ont été stimulées au BTH, puis inoculées par C. gloeosporioides $(\mathrm{St}+\mathrm{I})$, on a noté une augmentation progressive de cette teneur dans les deux organes des trois variétés. Au niveau des feuilles de la variété TMS 96/0023, elle est passée de 3,54 $\pm 0,63 \mu \mathrm{g}$ équivalent (+)- catéchine. $\mathrm{mg}^{-1} \mathrm{PF}$ au jour 0 à $13,71 \pm 0,00 \mu \mathrm{g}$ équivalent $(+)$ - catéchine. $\mathrm{mg}^{-1}$ $\mathrm{PF}$ au jour 8 , tandis qu'au niveau des tiges un pic de chute a été noté au jour $2(1,44 \pm 0,90 \mu \mathrm{g}$ équivalent (+)- catéchine. $\left.\mathrm{mg}^{-1} \mathrm{PF}\right)$. Chez la variété TMS 95/0326, la même tendance a été observée au niveau des feuilles, elle a été de
$2,17 \pm 0,19 \mu$ g équivalent $(+)$ - catéchine. $\mathrm{mg}^{-1} \mathrm{PF}$ au jour 0 à 13,58 $\pm 0,14 \mu \mathrm{g}$ équivalent $(+)$ catéchine. $\mathrm{mg}^{-1} \mathrm{PF}$ au jour 8 , par contre on a noté un pic de chute au jour $2(0,41 \pm 0,05 \mu \mathrm{g}$ équivalent (+)- catéchine. $\left.\mathrm{mg}^{-1} \mathrm{PF}\right)$. Chez la variété TMS 95/0211, on a enregistré un pic maximal au jour $2(11,72 \pm 1,07 \mu \mathrm{g}$ équivalent (+)- catéchine. $\left.\mathrm{mg}^{-1} \quad \mathrm{PF}\right)$ puis baisse progressivement, alors qu'au niveau des tiges, l'augmentation a été progressive et significative $\quad(\mathrm{p}<0,05) \quad(3,61 \pm 1,20 \quad \mu \mathrm{g}$ équivalent (+)- catéchine. $\mathrm{mg}^{-1} \mathrm{PF}$ au jour 0 à $11,18 \pm 0,57 \mu \mathrm{g}$ équivalent $(+)$ - catéchine. $\mathrm{mg}^{-1}$ $\mathrm{PF}$ au jour 8) (Tableaux 5 et 6 ).

Tableau 1 : Activité polyphénoloxydasique soluble (PPO) $\left(\mu \mathrm{M} \cdot \mathrm{mn}^{-1} \cdot \mathrm{ml}^{-1}\right)$ dans les feuilles de $M$. esculenta TMS 96/0023, TMS 92/0326 et TMS 95/0211. Plantes saines (S), inoculées (I), stimulées au BTH (St) et stimulées au BTH après inoculation avec $C$. gloeosporioides $(\mathrm{St+I})$.

\begin{tabular}{|c|c|c|c|c|}
\hline \multirow[b]{2}{*}{$\begin{array}{l}\text { Jours } \\
\text { après traitement }\end{array}$} & \multirow{2}{*}{ Traitements } & \multicolumn{3}{|c|}{ Variétés } \\
\hline & & TMS 96/0023 & TMS 92/0326 & TMS 95/0211 \\
\hline \multirow{4}{*}{0} & $S$ & $4,90 \pm 0,74^{b}$ & $3,74 \pm 0,14^{\mathrm{b}}$ & $3,47 \pm 0,40^{\mathrm{c}}$ \\
\hline & I & $5,33 \pm 1,24^{\mathrm{ab}}$ & $3,99 \pm 0,18^{b}$ & $3,51 \pm 0,39^{d}$ \\
\hline & $\mathrm{St}$ & $5,79 \pm 0,07^{\mathrm{ab}}$ & $3,25 \pm 0,21^{\mathrm{c}}$ & $6,49 \pm 0,56^{\mathrm{b}}$ \\
\hline & $\mathrm{St}+\mathrm{I}$ & $7,37 \pm 0,88^{\mathrm{a}}$ & $5,36 \pm 0,07^{\mathrm{a}}$ & $8,50 \pm 1,45^{\mathrm{a}}$ \\
\hline \multirow{4}{*}{2} & $\mathrm{~S}$ & $5,12 \pm 0,53^{b}$ & $4,08 \pm 0,83^{c}$ & $4,63 \pm 0,70^{c}$ \\
\hline & I & $5,40 \pm 1,65^{\mathrm{b}}$ & $3,88 \pm 0,21^{\mathrm{c}}$ & $4,16 \pm 0,21^{\mathrm{d}}$ \\
\hline & St & $6,22 \pm 1,71^{\mathrm{a}}$ & $4,34 \pm 0,60^{\mathrm{b}}$ & $5,19 \pm 0,05^{\mathrm{b}}$ \\
\hline & $\mathrm{St}+\mathrm{I}$ & $6,21 \pm 1,06^{\mathrm{a}}$ & $5,93 \pm 0,07^{\mathrm{a}}$ & $7,73 \pm 0,11^{\mathrm{a}}$ \\
\hline \multirow{4}{*}{4} & $\mathrm{~S}$ & $5,68 \pm 0,11^{\mathrm{c}}$ & $4,87 \pm 0,25^{\mathrm{d}}$ & $4,99 \pm 0,05^{\mathrm{c}}$ \\
\hline & I & $7,16 \pm 0,11^{\mathrm{b}}$ & $5,12 \pm 0,11^{\mathrm{c}}$ & $4,69 \pm 0,11^{\mathrm{d}}$ \\
\hline & $\mathrm{St}$ & $8,12 \pm 0,35^{\mathrm{a}}$ & $7,37 \pm 0,04^{\mathrm{b}}$ & $7,97 \pm 0,28^{\mathrm{a}}$ \\
\hline & $\mathrm{St}+\mathrm{I}$ & $8,01 \pm 0,11^{\mathrm{a}}$ & $7,83 \pm 0,10^{\mathrm{a}}$ & $7,13 \pm 0,07^{\mathrm{b}}$ \\
\hline \multirow{4}{*}{6} & $\mathrm{~S}$ & $6,18 \pm 0,18^{c}$ & $5,16 \pm 1,62^{c}$ & $5,39 \pm 0,40^{c}$ \\
\hline & I & $5,54 \pm 0,25^{\mathrm{b}}$ & $5,61 \pm 0,11^{\mathrm{ab}}$ & $5,01 \pm 0,64^{\mathrm{d}}$ \\
\hline & St & $7,66 \pm 1,09^{\mathrm{a}}$ & $6,99 \pm 0,71^{\mathrm{a}}$ & $7,62 \pm 0,49^{a}$ \\
\hline & $\mathrm{St}+\mathrm{I}$ & $6,74 \pm 0,18^{\mathrm{ab}}$ & $6,07 \pm 0,28^{b}$ & $6,39 \pm 0,60^{\mathrm{b}}$ \\
\hline \multirow{4}{*}{8} & $\mathrm{~S}$ & $6,35 \pm 0,07^{\mathrm{d}}$ & $6,66 \pm 1,01^{\mathrm{b}}$ & $6,19 \pm 1,14^{\mathrm{c}}$ \\
\hline & I & $9,32 \pm 0,21^{\mathrm{a}}$ & $5,75 \pm 0,04^{\mathrm{c}}$ & $5,36 \pm 0,28^{d}$ \\
\hline & St & $8,68 \pm 0,14^{\mathrm{b}}$ & $8,89 \pm 0,07^{\mathrm{a}}$ & $8,08 \pm 0,04^{\mathrm{b}}$ \\
\hline & $\mathrm{St}+\mathrm{I}$ & $8,29 \pm 0,60^{c}$ & $5,72 \pm 0,07^{\mathrm{c}}$ & $9,24 \pm 0,07^{\mathrm{a}}$ \\
\hline
\end{tabular}

Les valeurs portant la même lettre dans la même colonne pour chaque jour ne sont pas significativement différentes $(\mathrm{P}<0,05)$. Test de Tukey. 
Tableau 2 : Activité polyphénoloxydasique soluble (PPO) $\left(\mu \mathrm{M}_{\mathrm{mn}}{ }^{-1} \cdot \mathrm{ml}^{-1}\right)$ dans les tiges de $M$. esculenta TMS 96/0023, TMS 92/0326 et TMS 95/0211. Plantes saines (S), inoculées (I), stimulées au BTH (St) et stimulées au BTH après inoculation avec C. gloeosporioides $(\mathrm{St+I})$.

\begin{tabular}{|c|c|c|c|c|}
\hline \multirow{2}{*}{$\begin{array}{l}\text { Jours } \\
\text { après } \\
\text { traitement }\end{array}$} & \multirow{2}{*}{ Traitements } & \multicolumn{3}{|c|}{ Variétés } \\
\hline & & TMS 96/0023 & TMS 92/0326 & TMS 95/0211 \\
\hline \multirow{4}{*}{0} & $\mathrm{~S}$ & $3,39 \pm 0,00^{\mathrm{d}}$ & $3,17 \pm 1,52^{\mathrm{c}}$ & $3,02 \pm 1,58^{\mathrm{c}}$ \\
\hline & I & $3,90 \pm 1,06^{\mathrm{c}}$ & $3,43 \pm 0,01^{\mathrm{c}}$ & $3,07 \pm 0,32^{\mathrm{c}}$ \\
\hline & St & $4,02 \pm 1,27^{\mathrm{b}}$ & $4,27 \pm 1,31^{\mathrm{b}}$ & $4,09 \pm 0,20^{\mathrm{b}}$ \\
\hline & $\mathrm{St}+\mathrm{I}$ & $5,65 \pm 0,28^{\mathrm{a}}$ & $5,89 \pm 0,11^{\mathrm{a}}$ & $4,80 \pm 0,00^{\mathrm{a}}$ \\
\hline \multirow{4}{*}{2} & $\mathrm{~S}$ & $3,92 \pm 0,18^{c}$ & $3,44 \pm 1,23^{\mathrm{d}}$ & $3,22 \pm 0,93^{\mathrm{c}}$ \\
\hline & I & $4,80 \pm 0,04^{\mathrm{b}}$ & $4,82 \pm 3,34^{\mathrm{c}}$ & $3,32 \pm 0,35^{\mathrm{c}}$ \\
\hline & St & $4,90 \pm 0,74^{\mathrm{b}}$ & $7,06 \pm 0,50^{\mathrm{a}}$ & $6,46 \pm 1,66^{\mathrm{b}}$ \\
\hline & $\mathrm{St}+\mathrm{I}$ & $8,08 \pm 1,24^{\mathrm{a}}$ & $6,00 \pm 0,35^{\mathrm{b}}$ & $6,70 \pm 0,64^{a}$ \\
\hline \multirow{4}{*}{4} & $\mathrm{~S}$ & $4,89 \pm 0,14^{\mathrm{c}}$ & $3,73 \pm 0,25^{\mathrm{b}}$ & $3,59 \pm 0,05^{\mathrm{c}}$ \\
\hline & I & $7,90 \pm 0,56^{\mathrm{b}}$ & $3,85 \pm 0,18^{c}$ & $3,62 \pm 0,05^{\mathrm{c}}$ \\
\hline & St & $9,03 \pm 0,21^{\mathrm{a}}$ & $8,36 \pm 0,04^{\mathrm{a}}$ & $8,08 \pm 0,04^{\mathrm{b}}$ \\
\hline & $\mathrm{St}+\mathrm{I}$ & $7,16 \pm 0,18^{\mathrm{b}}$ & $8,50 \pm 0,18^{a}$ & $8,86 \pm 0,04^{\mathrm{a}}$ \\
\hline \multirow{4}{*}{6} & $\mathrm{~S}$ & $5,29 \pm 0,00^{c}$ & $4,10 \pm 0,25^{\mathrm{c}}$ & $3,39 \pm 0,40^{\mathrm{d}}$ \\
\hline & I & $5,54 \pm 0,04 b^{c}$ & $4,27 \pm 0,11^{\mathrm{c}}$ & $3,95 \pm 0,15^{\mathrm{c}}$ \\
\hline & St & $6,25 \pm 0,18^{a b}$ & $7,26 \pm 1,85^{\mathrm{b}}$ & $6,95 \pm 0,21^{\mathrm{a}}$ \\
\hline & $\mathrm{St}+\mathrm{I}$ & $7,13 \pm 0,71^{\mathrm{a}}$ & $8,08 \pm 0,05^{\mathrm{a}}$ & $5,61 \pm 0,04^{\mathrm{b}}$ \\
\hline \multirow{4}{*}{8} & $S$ & $5,54 \pm 0,04^{\mathrm{c}}$ & $4,32 \pm 0,25^{\mathrm{d}}$ & $3,49 \pm 0,39^{d}$ \\
\hline & I & $6,10 \pm 0,32^{\mathrm{bc}}$ & $4,90 \pm 0,32^{\mathrm{c}}$ & $9,21 \pm 0,39^{c}$ \\
\hline & St & $6,60 \pm 0,32^{\mathrm{b}}$ & $7,73 \pm 0,04^{\mathrm{b}}$ & $11,93 \pm 0,25^{\mathrm{a}}$ \\
\hline & $\mathrm{St}+\mathrm{I}$ & $7,80 \pm 0,18^{\mathrm{a}}$ & $9,07 \pm 0,32^{\mathrm{a}}$ & $9,63 \pm 0,21^{\mathrm{c}}$ \\
\hline
\end{tabular}

Les valeurs portant la même lettre dans la même colonne pour chaque jour ne sont pas significativement différentes $(\mathrm{P}<0,05)$. Test de Tukey.

Tableau 3: Activité de peroxydase soluble (POX) $\left(\mu \mathrm{M} \cdot \mathrm{mn}^{-1} \cdot \mathrm{ml}^{-1}\right)$ dans les feuilles de $M$. esculenta TMS 96/0023, TMS 92/0326 et TMS 95/0211. Plantes saines (S), inoculées (I), stimulées au BTH (St) et stimulées au BTH après inoculation avec C. gloeosporioides $(\mathrm{St}+\mathrm{I})$.

\begin{tabular}{ccccc}
\hline \multirow{2}{*}{$\begin{array}{c}\text { Jours } \\
\text { après }\end{array}$} & Traitements & & \multicolumn{3}{c}{ Variétés } \\
\cline { 3 - 5 } traitement & & TMS 96/0023 & TMS 92/0326 & TMS 95/0211 \\
\hline \multirow{2}{*}{0} & $\mathrm{~S}$ & $0,97 \pm 0,17^{\mathrm{d}}$ & $0,96 \pm 0,01^{\mathrm{c}}$ & $0,92 \pm 0,20^{\mathrm{d}}$ \\
& $\mathrm{I}$ & $1,67 \pm 0,02^{\mathrm{b}}$ & $1,36 \pm 0,21^{\mathrm{b}}$ & $1,27 \pm 0,22^{\mathrm{c}}$
\end{tabular}




\begin{tabular}{|c|c|c|c|c|}
\hline & St & $1,41 \pm 0,07^{\mathrm{c}}$ & $1,08 \pm 0,03^{c}$ & $1,42 \pm 0,37^{b}$ \\
\hline & $\mathrm{St}+\mathrm{I}$ & $1,75 \pm 0,21^{\mathrm{a}}$ & $1,81 \pm 0,42^{\mathrm{a}}$ & $2,08 \pm 0,27^{a}$ \\
\hline & $\mathrm{S}$ & $1,01 \pm 0,02^{\mathrm{d}}$ & $1,07 \pm 0,01^{\mathrm{d}}$ & $0,97 \pm 0,02^{\mathrm{c}}$ \\
\hline 2 & I & $1,82 \pm 0,09^{b}$ & $1,64 \pm 0,10^{\mathrm{b}}$ & $2,49 \pm 0,04^{\mathrm{a}}$ \\
\hline 2 & St & $1,57 \pm 0,11^{\mathrm{c}}$ & $1,43 \pm 0,19^{c}$ & $2,29 \pm 0,12^{b}$ \\
\hline & $\mathrm{St}+\mathrm{I}$ & $2,39 \pm 0,02^{\mathrm{a}}$ & $1,99 \pm 0,13^{\mathrm{a}}$ & $2,34 \pm 0,01^{b}$ \\
\hline & $S$ & $1,17 \pm 0,01^{\mathrm{d}}$ & $1,10 \pm 0,00^{\mathrm{c}}$ & $1,06 \pm 0,02^{\mathrm{d}}$ \\
\hline 4 & I & $1,93 \pm 0,23^{\mathrm{c}}$ & $0,14 \pm 0,04^{\mathrm{d}}$ & $2,73 \pm 0,02^{a}$ \\
\hline 4 & St & $2,33 \pm 0,80^{b}$ & $1,85 \pm 0,15^{b}$ & $2,41 \pm 0,22^{\circ}$ \\
\hline & $\mathrm{St}+\mathrm{I}$ & $2,49 \pm 0,02^{\mathrm{a}}$ & $2,14 \pm 0,10^{\mathrm{a}}$ & $2,66 \pm 0,01^{b}$ \\
\hline & $\mathrm{S}$ & $1,28 \pm 0,05^{\mathrm{d}}$ & $1,09 \pm 0,14^{\mathrm{a}}$ & $1,04 \pm 0,01^{\circ}$ \\
\hline 6 & I & $1,67 \pm 0,15^{\mathrm{c}}$ & $0,18 \pm 0,01^{\mathrm{c}}$ & $1,45 \pm 0,44^{b}$ \\
\hline 0 & St & $2,53 \pm 0,55^{\mathrm{b}}$ & $0,54 \pm 0,15^{\mathrm{b}}$ & $0,59 \pm 0,25^{\mathrm{d}}$ \\
\hline & $\mathrm{St}+\mathrm{I}$ & $3,13 \pm 0,25^{\mathrm{a}}$ & $0,23 \pm 0,09^{c}$ & $1,59 \pm 0,15^{\mathrm{a}}$ \\
\hline & $S$ & $1,32 \pm 0,06^{\mathrm{d}}$ & $1,28 \pm 0,10^{b}$ & $1,09 \pm 0,18^{b}$ \\
\hline 8 & I & $1,41 \pm 0,33^{\mathrm{c}}$ & $1,30 \pm 0,02^{b}$ & $0,76 \pm 0,20^{\circ}$ \\
\hline & St & $2,71 \pm 0,14^{\mathrm{a}}$ & $0,55 \pm 0,05^{\mathrm{c}}$ & $0,94 \pm 0,07^{\circ}$ \\
\hline & $\mathrm{St}+\mathrm{I}$ & $1,78 \pm 0,85^{b}$ & $1,76 \pm 0,73^{\mathrm{a}}$ & $1,79 \pm 0,25^{a}$ \\
\hline
\end{tabular}

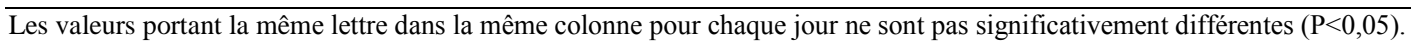
Test de Tukey.

Tableau 4 : Activité de peroxydase soluble (POX) $\left(\mu \mathrm{M}_{\mathrm{mn}}{ }^{-1} \cdot \mathrm{ml}^{-1}\right)$ dans les tiges de M. esculenta TMS 96/0023, TMS 92/0326 et TMS 95/0211. Plantes saines (S), inoculées (I), stimulées au BTH (St) et stimulées au BTH après inoculation avec C. gloeosporioides $(\mathrm{St}+\mathrm{I})$.

\begin{tabular}{clccc}
\hline \multirow{2}{*}{$\begin{array}{l}\text { Jours } \\
\text { après } \\
\text { traitement }\end{array}$} & Traitements & \multicolumn{3}{c}{ Variétés } \\
\cline { 3 - 5 } & & TMS 96/0023 & TMS 92/0326 & TMS 95/0211 \\
\hline \multirow{2}{*}{0} & $\mathrm{~S}$ & $1,41 \pm 0,04^{\mathrm{c}}$ & $1,32 \pm 0,04^{\mathrm{a}}$ & $1,16 \pm 0,10^{\mathrm{c}}$ \\
& $\mathrm{I}$ & $1,83 \pm 0,10^{\mathrm{a}}$ & $1,63 \pm 0,06^{\mathrm{b}}$ & $1,62 \pm 0,05^{\mathrm{b}}$ \\
& $\mathrm{St}$ & $1,64 \pm 0,09^{\mathrm{b}}$ & $1,61 \pm 0,31^{\mathrm{b}}$ & $1,95 \pm 0,16^{\mathrm{a}}$ \\
& $\mathrm{St}+\mathrm{I}$ & $1,78 \pm 0,17^{\mathrm{a}}$ & $1,69 \pm 0,05^{\mathrm{a}}$ & $1,98 \pm 0,05^{\mathrm{a}}$ \\
\hline & $\mathrm{S}$ & $1,48 \pm 0,14^{\mathrm{c}}$ & $1,37 \pm 0,01^{\mathrm{d}}$ & $1,28 \pm 0,06^{\mathrm{c}}$ \\
& $\mathrm{I}$ & $1,98 \pm 0,18^{\mathrm{b}}$ & $1,70 \pm 0,04^{\mathrm{c}}$ & $2,06 \pm 0,17^{\mathrm{a}}$ \\
& $\mathrm{St}$ & $2,08 \pm 0,07^{\mathrm{b}}$ & $1,94 \pm 0,05^{\mathrm{b}}$ & $1,79 \pm 0,90^{\mathrm{b}}$ \\
& $\mathrm{St}+\mathrm{I}$ & $2,41 \pm 1,75^{\mathrm{a}}$ & $2,11 \pm 0,50^{\mathrm{a}}$ & $0,73 \pm 0,09^{\mathrm{d}}$ \\
\hline \multirow{2}{*}{4} & $\mathrm{~S}$ & $1,61 \pm 0,05^{\mathrm{d}}$ & $1,52 \pm 0,05^{\mathrm{d}}$ & $1,50 \pm 0,03^{\mathrm{b}}$ \\
& $\mathrm{I}$ & $2,04 \pm 0,09^{\mathrm{c}}$ & $1,77 \pm 0,85^{\mathrm{c}}$ & $1,88 \pm 0,05^{\mathrm{a}}$
\end{tabular}




\begin{tabular}{cllll} 
& St & $2,25 \pm 0,30^{\mathrm{b}}$ & $1,84 \pm 0,15^{\mathrm{b}}$ & $0,27 \pm 0,02^{\mathrm{d}}$ \\
& $\mathrm{St}+\mathrm{I}$ & $2,56 \pm 0,25^{\mathrm{a}}$ & $2,37 \pm 0,60^{\mathrm{a}}$ & $0,87 \pm 0,23^{\mathrm{c}}$ \\
\hline \multirow{3}{*}{6} & $\mathrm{~S}$ & $1,73 \pm 0,06^{\mathrm{d}}$ & $1,86 \pm 0,06^{\mathrm{d}}$ & $1,64 \pm 0,17^{\mathrm{d}}$ \\
& $\mathrm{I}$ & $2,14 \pm 0,05^{\mathrm{c}}$ & $1,98 \pm 0,60^{\mathrm{c}}$ & $1,74 \pm 0,15^{\mathrm{c}}$ \\
& $\mathrm{St}$ & $2,65 \pm 0,11^{\mathrm{b}}$ & $2,78 \pm 0,85^{\mathrm{b}}$ & $2,05 \pm 0,15^{\mathrm{b}}$ \\
& $\mathrm{St}+\mathrm{I}$ & $3,50 \pm 0,32^{\mathrm{a}}$ & $3,08 \pm 0,05^{\mathrm{a}}$ & $2,84 \pm 3,74^{\mathrm{a}}$ \\
\hline \multirow{2}{*}{8} & $\mathrm{~S}$ & $2,06 \pm 0,25^{\mathrm{a}}$ & $1,94 \pm 0,45^{\mathrm{d}}$ & $1,89 \pm 0,19^{\mathrm{d}}$ \\
& $\mathrm{I}$ & $2,92 \pm 0,15^{\mathrm{b}}$ & $2,04 \pm 1,05^{\mathrm{c}}$ & $3,21 \pm 0,35^{\mathrm{c}}$ \\
& $\mathrm{St}$ & $3,01 \pm 0,45^{\mathrm{b}}$ & $2,99 \pm 0,45^{\mathrm{b}}$ & $3,43 \pm 0,30^{\mathrm{b}}$ \\
& $\mathrm{St}+\mathrm{I}$ & $3,66 \pm 0,25^{\mathrm{a}}$ & $3,19 \pm 0,10^{\mathrm{a}}$ & $3,93 \pm 1,15^{\mathrm{a}}$
\end{tabular}

Les valeurs portant la même lettre dans la même colonne pour chaque jour ne sont pas significativement différentes $(\mathrm{P}<0,05)$. Test de Tukey.

Tableau 5: Variation de la teneur des composés phénoliques solubles ( $\mu$ g équivalent $(+)$ catéchine.mg ${ }^{-1} \mathrm{PF}$ ) dans les feuilles de $M$. esculenta, TMS 96/0023, TMS 92/0326 et TMS 95/0211. Plantes saines (S), inoculées (I), stimulées au BTH (St) et stimulées au BTH après inoculation avec C. gloeosporioides $(\mathrm{St}+\mathrm{I})$.

\begin{tabular}{|c|c|c|c|c|}
\hline \multirow{2}{*}{$\begin{array}{l}\text { Jours } \\
\text { après } \\
\text { traitement }\end{array}$} & \multirow{2}{*}{ Traitements } & \multicolumn{3}{|c|}{ Variétés } \\
\hline & & TMS 96/0023 & TMS 92/0326 & TMS 95/0211 \\
\hline \multirow{4}{*}{0} & $\mathrm{~S}$ & $6,19 \pm 1,27^{b}$ & $6,01 \pm 0,85^{\mathrm{c}}$ & $5,76 \pm 0,29^{c}$ \\
\hline & I & $9,61 \pm 0,29^{\mathrm{a}}$ & $7,78 \pm 0,32^{\mathrm{b}}$ & $8,67 \pm 3,64^{a}$ \\
\hline & St & $11,21 \pm 0,01^{\mathrm{a}}$ & $11,36 \pm 1,90^{\mathrm{a}}$ & $7,59 \pm 2,20^{\mathrm{b}}$ \\
\hline & $\mathrm{St}+\mathrm{I}$ & $3,54 \pm 0,03^{\mathrm{c}}$ & $2,17 \pm 0,19^{d}$ & $2,64 \pm 0,07^{\mathrm{d}}$ \\
\hline \multirow{4}{*}{2} & $S$ & $7,46 \pm 0,18^{\mathrm{a}}$ & $7,02 \pm 1,80^{\mathrm{b}}$ & $6,03 \pm 0,58^{b}$ \\
\hline & I & $7,84 \pm 0,85^{\mathrm{a}}$ & $9,46 \pm 0,04^{\mathrm{a}}$ & $5,86 \pm 0,09^{b}$ \\
\hline & St & $3,99 \pm 1,48^{\mathrm{b}}$ & $5,96 \pm 1,18^{c}$ & $3,55 \pm 0,09^{c}$ \\
\hline & $\mathrm{St}+\mathrm{I}$ & $3,80 \pm 2,61^{b}$ & $3,81 \pm 0,45^{\mathrm{d}}$ & $11,72 \pm 1,07^{\mathrm{a}}$ \\
\hline \multirow{4}{*}{4} & $\mathrm{~S}$ & $8,86 \pm 1,06^{\mathrm{b}}$ & $7,34 \pm 0,75^{\mathrm{a}}$ & $6,76 \pm 2,12^{\mathrm{d}}$ \\
\hline & I & $9,55 \pm 0,58^{\mathrm{a}}$ & $4,43 \pm 1,14^{\mathrm{c}}$ & $9,10 \pm 3,53^{b}$ \\
\hline & St & $5,12 \pm 0,09^{c}$ & $5,19 \pm 1,80^{\mathrm{b}}$ & $9,34 \pm 2,46^{a}$ \\
\hline & $\mathrm{St}+\mathrm{I}$ & $4,53 \pm 0,07^{\mathrm{d}}$ & $7,31 \pm 0,17^{\mathrm{a}}$ & $8,12 \pm 1,27^{\mathrm{c}}$ \\
\hline \multirow{4}{*}{6} & $\mathrm{~S}$ & $9,84 \pm 0,36^{\mathrm{ac}}$ & $9,41 \pm 0,17^{b}$ & $8,14 \pm 0,27^{b}$ \\
\hline & I & $11,71 \pm 0,29^{b}$ & $8,89 \pm 0,02^{\mathrm{c}}$ & $8,86 \pm 0,72^{\mathrm{a}}$ \\
\hline & St & $12,16 \pm 0,28^{a}$ & $6,16 \pm 0,57^{d}$ & $4,13 \pm 0,39^{d}$ \\
\hline & $\mathrm{St}+\mathrm{I}$ & $6,86 \pm 2,07^{\mathrm{d}}$ & $11,26 \pm 0,14^{\mathrm{a}}$ & $5,47 \pm 0,22^{\mathrm{c}}$ \\
\hline 8 & $\mathrm{~S}$ & $10,19 \pm 2,12^{b}$ & $9,57 \pm 0,35^{\mathrm{d}}$ & $8,68 \pm 0,09^{c}$ \\
\hline
\end{tabular}


H. D.B. ELIAN et al. / Int. J. Biol. Chem. Sci. 15(3): 950-965, 2021

$\begin{array}{lccc}\text { I } & 5,76 \pm 1,41^{\mathrm{c}} & 12,98 \pm 0,01^{\mathrm{b}} & 9,52 \pm 2,44^{\mathrm{b}} \\ \text { St } & 10,43 \pm 0,42^{\mathrm{b}} & 11,23 \pm 0,64^{\mathrm{c}} & 10,06 \pm 0,53^{\mathrm{a}} \\ \mathrm{St}+\mathrm{I} & 13,71 \pm 0,00^{\mathrm{a}} & 13,58 \pm 0,14^{\mathrm{a}} & 8,11 \pm 0,70^{\mathrm{d}}\end{array}$

Les valeurs portant la même lettre dans la même colonne pour chaque jour ne sont pas significativement différentes $(\mathrm{P}<0,05)$. Test de Tukey.

Tableau 6: Variation de la teneur des composés phénoliques solubles ( $\mu \mathrm{g}$ équivalent $(+)$ catéchine. $\mathrm{mg}^{-1} \mathrm{PF}$ ) dans les tiges de M. esculenta, TMS 96/0023, TMS 92/0326 et TMS 95/0211. Plantes saines (S), inoculées (I), stimulées au BTH (St) et stimulées au BTH après inoculation avec C. gloeosporioides $(\mathrm{St}+\mathrm{I})$.

\begin{tabular}{|c|c|c|c|c|}
\hline \multirow{2}{*}{$\begin{array}{l}\text { Jours } \\
\text { après } \\
\text { traitement }\end{array}$} & \multirow[t]{2}{*}{ Traitements } & \multicolumn{3}{|c|}{ Variétés } \\
\hline & & TMS 96/0023 & TMS 92/0326 & TMS 95/0211 \\
\hline \multirow{4}{*}{0} & $\mathrm{~S}$ & $6,51 \pm 1,07^{\mathrm{c}}$ & $4,00 \pm 0,33^{\mathrm{c}}$ & $3,38 \pm 0,04^{\mathrm{c}}$ \\
\hline & I & $9,86 \pm 0,12^{\mathrm{b}}$ & $6,54 \pm 2,37^{\mathrm{a}}$ & $10,01 \pm 1,70^{\mathrm{a}}$ \\
\hline & St & $6,43 \pm 0,49^{c}$ & $5,17 \pm 2,20^{\mathrm{b}}$ & $6,22 \pm 1,28^{b}$ \\
\hline & $\mathrm{St}+\mathrm{I}$ & $11,11 \pm 2,78^{\mathrm{a}}$ & $4,01 \pm 1,15^{\mathrm{c}}$ & $3,61 \pm 1,20^{\mathrm{c}}$ \\
\hline \multirow{4}{*}{2} & $S$ & $6,72 \pm 2,10^{\mathrm{a}}$ & $5,92 \pm 0,21^{\mathrm{a}}$ & $3,86 \pm 0,29^{b}$ \\
\hline & I & $1,04 \pm 0,36^{\mathrm{c}}$ & $2,19 \pm 0,65^{\mathrm{c}}$ & $3,91 \pm 1,63^{b}$ \\
\hline & St & $3,41 \pm 0,80^{\mathrm{b}}$ & $4,85 \pm 0,35^{\mathrm{b}}$ & $3,40 \pm 0,26^{\mathrm{b}}$ \\
\hline & $\mathrm{St}+\mathrm{I}$ & $1,44 \pm 0,90^{c}$ & $0,41 \pm 0,05^{\mathrm{d}}$ & $7,49 \pm 0,11^{\mathrm{a}}$ \\
\hline \multirow{4}{*}{4} & $\mathrm{~S}$ & $6,84 \pm 0,35^{\mathrm{c}}$ & $6,43 \pm 0,01^{\mathrm{c}}$ & $4,62 \pm 0,02^{\mathrm{d}}$ \\
\hline & I & $10,44 \pm 0,94^{\mathrm{a}}$ & $10,75 \pm 2,06^{\mathrm{a}}$ & $6,23 \pm 0,77^{\mathrm{c}}$ \\
\hline & St & $8,35 \pm 1,19^{\mathrm{c}}$ & $8,02 \pm 3,48^{b}$ & $7,86 \pm 0,37^{\mathrm{a}}$ \\
\hline & $\mathrm{St}+\mathrm{I}$ & $9,67 \pm 2,33^{b}$ & $8,01 \pm 0,22^{\mathrm{b}}$ & $7,67 \pm 0,20^{\mathrm{a}}$ \\
\hline \multirow{4}{*}{6} & $S$ & $7,12 \pm 1,06^{\mathrm{b}}$ & $7,01 \pm 2,06^{\mathrm{c}}$ & $4,70 \pm 0,14^{\mathrm{c}}$ \\
\hline & I & $9,41 \pm 1,24^{\mathrm{a}}$ & $8,40 \pm 0,51^{\mathrm{b}}$ & $9,92 \pm 0,08^{\mathrm{a}}$ \\
\hline & St & $9,71 \pm 0,46^{\mathrm{a}}$ & $0,98 \pm 0,09^{d}$ & $2,42 \pm 0,91^{\mathrm{d}}$ \\
\hline & $\mathrm{St}+\mathrm{I}$ & $4,84 \pm 2,06^{c}$ & $11,77 \pm 1,54^{\mathrm{a}}$ & $8,62 \pm 1,98^{b}$ \\
\hline \multirow{4}{*}{8} & $S$ & $7,33 \pm 0,73^{b}$ & $7,17 \pm 1,57^{\mathrm{d}}$ & $4,79 \pm 1,27^{\mathrm{d}}$ \\
\hline & I & $3,03 \pm 0,03^{c}$ & $8,69 \pm 1,78^{c}$ & $6,87 \pm 0,90^{c}$ \\
\hline & St & $7,88 \pm 0,17^{b}$ & $11,07 \pm 0,93^{\mathrm{a}}$ & $8,01 \pm 0,12^{\mathrm{b}}$ \\
\hline & $\mathrm{St}+\mathrm{I}$ & $13,91 \pm 0,22^{\mathrm{a}}$ & $9,44 \pm 0,29^{b}$ & $11,18 \pm 0,57^{\mathrm{a}}$ \\
\hline
\end{tabular}

Les valeurs portant la même lettre dans la même colonne pour chaque jour ne sont pas significativement différentes $(\mathrm{P}<0,05)$. Test de Turkey. 


\section{DISCUSSION}

Plusieurs auteurs dans les études antérieures ont montré l'implication des PPO et des POX dans la résistance des plantes. Ils ont montré que ces enzymes sont impliquées dans plusieurs fonctions entre autres, les mécanismes de défenses contre les agents pathogènes avirulents ou virulents (Housti et al., 2002; Constabel et al., 2000; Kuwabara et al., 1999). Chez les plantes saines, les variétés TMS 96/0023 et 92/0326 ont des activités spécifiques de PPO et POX élevées par rapport à celle de TMS 95/0211 au niveau des feuilles et des tiges. La teneur en PPO et celle en POX sont plus importants dans les plantes stimulées et en condition d'inoculation comparée aux témoins dans les deux organes de la plante chez les trois variétés. Cette hausse est plus importante chez la variété TMS 95/0211 au jour 8 au niveau des feuilles et des tiges. Ceci serait lié à une situation d'hypersensibilité de cette variété. Pour Mbouobda (2013), cette augmentation de la teneur en PPO et POX impliquerait le stress oxydatif avec l'action de l'activité de POX comme réponse antioxydant. Ces deux enzymes jouent un rôle important dans le mécanisme de défenses des plantes en réponse à diverses conditions de stress (Kim et al., 2010). Leur activation en cas de stress est la conséquence de l'élimination de l' $\mathrm{H}_{2} \mathrm{O}_{2}$ et la lignification des racines, comme réaction de défense (Haluskova et al., 2010). La capacité de BTH à induire la résistance systémique acquise (RSA) a été démontrée par Benhamou and Belanger (1998) sur le concombre (Cucumis sativus); Matheron et Porchas (2002) sur le piment (Capsicum annuum); Mbouobda (2013) sur le macabo (Xanthosoma sagittifolium). En outre, chez la plupart des plantes étudiées, l'expression des gènes induits par le BTH est éphémère ou transitoire (Zhu et al., 2003). Les résultats de ces travaux démontrent que les trois variétés sont fortement stimulées par le BTH puis par le BTH suivie de l'inoculation par $C$. gloeosporioides au niveau des feuilles et des tiges. Ces résultats sont comparables à ceux obtenus par Mbouobda (2013) qui a observé une accumulation de PPO et POX, après stimulation au BTH dans l'interaction $\quad X . \quad$ sagittifolium/Pythium myriotylum.

En effet, les POX sont impliquées dans le mécanisme de défense des plantes, et l'augmentation de l'activité en réponse à l'inoculation ou à la stimulation peut être corrélée au pathosystème et au niveau de résistance de l'hôte (Delannoy et al., 2006). La variété TMS 96/0023, résistante et TMS 92/0326, tolérante, au niveau des feuilles et des tiges enregistrent une quantité de POX sans ou avec nécrose de petites surfaces ou diamètres de lésions nécrotiques contrairement à la variété TMS 95/0211, sensible, qui accumule une grande quantité de l'activité POX dans ces deux organes avec des grandes surfaces ou diamètres de lésions nécrotiques, d'où l'implication des POX dans la résistance et l'hypersensibilité. Ces résultats sont en accord avec ceux obtenus par Mbouobda (2010), qui ont montré une accumulation des POX dans les feuilles et les racines de $X$. sagittifolium pour la résistance et contraire pour l'hypersensibilité.

L'accumulation des composés phénoliques par suite d'une infection a été signalée par de nombreux auteurs. Mbouobda (2013) a noté une accumulation de la synthèse des composés phénoliques dans l'interaction Xanthosoma sagittifolium/Pythium myriotilum. Omokolo et al. (1996) et Nana (1991) ont enregistré une stimulation de la synthèse des composés phénoliques chez Theobroma cacao après infection par Phytophtora megakarya. Cherif et al. (1994) ont observé des phénols préexistants dans les racines de Cucumis sativus après infection par Aphani dermatum et Pythium ultimum. Toutefois, comme semble être le cas dans ce travail, la résistance n'est pas toujours corrélée à la quantité de phénols, mais plutôt à la nature des phénols accumulée. En effet, Nguefack (1994), en étudiant l'interaction Theobroma cacao/Phytophtora megakarya a observé une accumulation intense des flavonols au niveau des cabosses des clones résistants après infection.

\section{Conclusion}

L'induction de la résistance à l'anthracnose due à $C$. gloeosporioides est due à l'activation de certaines enzymes de défense 
POX et PPO, et d'une accumulation des composés phénoliques dans les feuilles et tiges. L'évaluation de l'activité de la POX, des PPO et de la teneur en composés phénoliques totaux solubles des feuilles et des tiges étudiées permet de comparer et de classifier les différentes variétés. Ces paramètres physiologiques ont été examinés avant et après la stimulation au BTH et/ou l'inoculation par C. gloeosporioides. Aussi, la variété TMS 96/0023 et TMS 92/0326 sont classées dans la catégorie des résistantes ou tolérantes présentant à la fois une quantité élevée de composés phénoliques totaux solubles et une forte activation des PPO. La variété TMS 95/0211 qui a eu l'un des facteurs (activité de POX, des PPO ou teneur en composés phénoliques totaux solubles) maintenu à un niveau parfois élevé ou moins élevé est considéré comme hypersensible. De ces résultats, nous concluons que l'agent fongique responsable des symptômes de l'anthracnose du manioc peut être stimulé par un traitement au BTH qui est un éliciteur des protéines de résistance.

\section{CONFLIT D'INTERETS} conflit d'intérêts.

\section{CONTRIBUTIONS DES AUTEURS}

EHD, DDM et DAC ont réalisé toutes les activités (conception, culture des trois variétés, analyse biochimique, traitement statistiques des données et rédaction de ce manuscrit) de cette étude. FOTSO et OND sont des Co-encadreurs de cette étude.

\section{REMERCIEMENTS}

Ce travail a bénéficié du soutien financier de la Coopération Française via l'Ambassade de France à Bangui.

\section{REFERENCES}

Benhamou N, Belanger R. 1998. Benzothiazole-mediated induced resistance to Fusarium oxysporum f. sp radicis-lycopersici in tomato. Plant Physiology, 118: 1203-1212. DOI:
https://dx.doi.org/10.1104\%2Fpp.118.4.1 203

Cherif J, Mediouni C, Ammar WB, Jemal F. 1994. Interaction of Zinc and Cadnium toxicity in their effects on growth and in antioxydative system in tomato plant (Solanum lycopersicum). J. environ. Sci., 23: $\quad 837-844 . \quad$ DOI: https://doi.org/10.1016/S10010742(10)60415-9

Colak A, Özen A, Dincer B, Güner S, Ayaz A, 2005. Diphenolases from two cultivars of cherry laurel (Laurocerasus officinalis Roem.) fruit at an early stage of maturation. Food Chem., 90: 801-807. DOI:

https://doi.org/10.1016/j.foodchem.2004. 06.004

Concellün A, Aòün MC, Chaves AR. 2004. Characterization and changes in polyphenol oxidase from eggplant fruit (Solanum melongena L.) during storage at low temperature. Food Chem., 88: 17-24. DOI:

https://doi.org/10.1016/j.foodchem.2004. 01.017

Constabel CP, Lynn Y, Patton JJ, Christopher M.E. 2000. Polyphenol oxidase from hybrid poplar. Cloning and expression in response to wounding and herbivory. Plant. Physiol., 124: 285-295. DOI : https://doi.org/10.1104/pp.124.1.285

Coulibaly N, Séry Z, 1992. Situation de la culture et de la recherche sur le manioc en Côte d'Ivoire. IDESSA. p. 6.

Delannoy E, Marmey P, Jalloul A, Etienne H, Nicole M. 2006. Molecular analysis of Classe III Peroxydases from Cotton. Molecular Biology and Physiology. The Journal of Cotton Science, 10: 53-60.

Djocgoue PF, Boudjeko T, Mbouobda HD, Nankeu DJ, El Hadrami I, Omokolo ND. 2007. Heritability of phenol in the resistance of Theobroma cacao against Phytophtora megakarya, the causal agent of black pod disease. Journal of Phytopathology, 155: 519-525. DOI: https://doi.org/10.1111/j.14390434.2007.01268.x 
Dogbo DO, Bekro MJA, Bekro YA, Sie RS, Gogbeu SJ, Traore A. 2008. Influence de l'acide salicylique sur la synthèse de la phénylalanine ammonia-lyase, des polyphénoloxydases et l'accumulation des composés phénoliques chez le manioc (Manihot esculenta Crantz). Sciences \& Nature, 5(1): 1-13.

Elian HDB. 2017. Micropropagation du manioc (Manihot esculenta Crantz) et évaluation des marqueurs biochimiques de résistance à Colletotrichum gloeosporioides Penz. These de Doctorat/Ph.D. Université de Yaoundé 1. 143p.

Gümez-Vásquez R, Day R, Buschmann H, Randles S, Beeching JR, Cooper R., 2004. Phenylpropanoids, phenylalanine ammonia-lyase and peroxidases in elicitor-challenged cassava (Manihot esculenta Crantz) suspension cells and leaves. Ann. Bot., 94: 87-97. DOI : https://doi.10.1093/aob/mch107.

Guthrie J. 2004. Contrôler la Mosaïque Africaine du Manioc. Centre technique de coopération agricole et rurale. Chayce Publication Services, Royaume-Uni. P .98 .

Haluskova L, Venlatovicova K, Huttova J, Mistrik I, Tamas L. 2010. Effect of heavy metals on root growth and peroxidase activity in barley root typ. Acta. Physiol. Plant., 32: 59-65. DOI: https://doi.org/10.1007/s11738-0090377-1

He CY, Hsiang T, Wolyn DJ. 2002. Induction of systemic disease resistance and pathogen defence responses in Asparagus officinalis inoculated with nonpathogenic strains of Fusarium oxysporum. Plant Pathol., 51: 225-230. DOI: https://doi.org/10.1046/j.13653059.2002.00682.x

Housti F, Andary C, Gargadenne A, Amssa M. 2002. Effects of wounding and salicylic acid on hydroxycinnamocylmalic acids in Thunbergia alata. Plant. Physiol. Biochem., 40: 761-769.

Jourdan E, Ongena M, Thonart P. 2008. Caractéristiques moléculaires de l'immunité induite des plantes induite par les rhizobacteries non pathogènes. Biotechnol. Agron. Soc. Environ., 12(4): 437-449.

Kim YH, Lee HS, Kwak SS. 2010. Differential responses of Sweet potato peroxidases to heavy metals. Chemosphere, 81: 79-85. DOI:

https://doi.org/10.1016/j.chemosphere.20 10.06 .063

Kumba K. 2012. Genetic characterization of exotic and landraces of cassava in Ghana. M.Sc., in Agronomy, Kwamenkrumah University of Science and Technology, $111 \mathrm{p}$.

Kuwabara T, Katoh Y, 1999. Involvement of the binuclear copper site in the proteolytic activity of polyphenoloxidase. Plant Cell Physiol., 40: 1029-1035. DOI: https://doi.org/10.1093/oxfordjournals.pc p.a029484

Majourhat K, Baaziz M, Bendiab K. 2002. In Actes du "Congres de Biochimie, Casablanca, 9, 10, 11 mai 2002", Biochimie et Environnement 86-90. Ed. Société Marocaine de Biochimie; p. 87.

Makambila C. 1984. Epidemiology of anthracnose in cassava. In: Root Crops: Production and Uses in Africa. Terry ER, Doku EV, Arene OB, Mahungu NM (Eds.). ISTRC : Canada; 73-78.

Marigo G. 1973. Sur une méthode de fractionnement et d'estimation des composés phénoliques chez les végétaux. Analysis, 2: 10-110.

Matheron ME, Porchas M. 2002. Suppression of phytophtora root and crown rot on pepper plant treated with acid benzolar-Smethyl. Plant Desease, 86: 292-297.

Mayer AM, Harel E, Shau RB. 1965. Assay of catechol oxidase, a critical comparison of methods. Phytochemistry, 5: 783-789. DOI: https://dx.doi.org/10.1016/S00319422 (00)83660-2

Mbouobda HD, Boudjeko T, Djocgoue PF, Tsafack TJJ, Omokolo ND. 2007. Morphological, characterisation and agronomic evaluation of cocoyam (Xanthosoma sagitifolium L. Schott) germplasm in Cameroun. Journal of 
Biological Sciences, 7(1): 27-33. DOI : https://doi.org/10.3923/jbs.2007.27.33.

Mbouobda HD, Fotso, Djocgoue PF. 2010. Benzo-(1,2,3)-thiadiazole-7-carbothioic S-methyl ester (BTH) stimulates defense reactions in Xanthosoma sagittifolium. Phytoparasitica, 38: 71-79. DOI : https://doi.org/10.1007/s12600-0090071-2.

Mbouobda HD. 2013. Stimulation des mécanismes de défense par Chitosane (CTH) et l'acide benzo $(1,2,3)$ thiadiazole -7 carbothionic-S- méthyl ester (BTH) dans l'interaction Xanthosoma sagitifolium (macabo)/Pythium myriotylum. Thèse de doctotat/Ph.D. Université de Yaoundé I. 140 p.

Nana. 1991. Composés phénoliques et résistance du cacaoyer (Theobroma cacao) au Phytophtora megakarya (Pouriture brune). Thèse de doctorat 3è cycle. Université de Yaoundé 1. p. 131 p. Nguefack J. 1994. Etudes des rélations hôtesparasites dans l'intéraction compatible entre Theobroma. Cacao et Phytophtora megakarya (Pouriture brune). Thèse de doctorat 3è cycle. Université de Yaoundé 1. p.117.

Nugroho LH, Verberne MC, Verpoorte R. 2002. Activities of enzymes involved in phenylpropanoid pathway in constituvelly salicylic acid-producing tobacco plants. Plant Physiol. Biochem., 40: 755-760. DOI : https://doi.org/10.1016/S098194285(02)01437-7.

Omokolo ND, Tsala NG, Djocgoue PF. 1996. Changes in carbohydrate, amino acid and phenol contents in cacao pods from three clones after infection with Phytopthtora megakarya Bras and Grif. Ann. Bot., 77: 153-158.

Ravi V, Aked J, Balagopalan C. 1996. Reviews on tropical root and tuber crops I. Storage methods and quality changes. Critical reviews. Food Sci. Nut., 36: 661-709. DOI:

https://doi.org/10.1080/10408399609527 745.

Schweiggert U, Schieber A, Carle R. 2005. Inactivation of peroxidase, polyphenol oxidase and lipoxygenase in paprika and chilli powder after immediate thermal treatment of the plant material. Innov. \$ Food. Sci. Emerging Technol., 6: 403411.

DOI: https://doi.org/10.1016/j.ifset.2005.05.00 1.

Thorpe TA, Tran Thanh Van KM, Gaspar T. 1978. Isoperoxidase in epidermal layers of tobacco and changes during organ formation in vitro. Physiol. Plant., 44: 388-394.

DOI: https://doi.org/10.1111/j.13993054.1978.tb01643.x.

Xiaochun D, Xiaoyang Z, Wang Z, Fengjun L, Shuangling X, Xuewu D. 2021. BTH Treatment Delays the Senescence of Postharvest Pitaya Fruit in Relation to Enhancing Antioxidant System and Phenylpropanoid Pathway. Foods, 13 : 10(4): $\quad 846 . \quad$ DOI: 10.3390/foods 10040846.

Zhu YJ, Xiaohui Q, Moore PH, Wayne Borth JH, Stephen F., Henrik HA. 2003. Systemic acquired resistance induced by BTH in papaya. Physiol. Mol. Plant. Pathol., 63: 237-248. 